Article

\title{
Adaptive Fuzzy Neural Network PID Algorithm for BLDCM Speed Control System
}

\author{
Hongqiao Yin ${ }^{1}\left(\mathbb{D}\right.$, Wenjun $\mathrm{Yi}^{1, *}$, Jintao $\mathrm{Wu}^{2}{ }^{2}$, Kangjian Wang ${ }^{1,3}$ and Jun Guan ${ }^{1,4} \mathbb{D}$ \\ 1 National Key Laboratory of Transient Physics, Nanjing University of Science and Technology, \\ Nanjing 210094, China; yinhongqiao3@njust.edu.cn (H.Y.); wkj@njust.edu.cn (K.W.); jguan@just.edu.cn (J.G.) \\ 2 Beijing Institute of Astronautical System Engineering, China Academy of Launch Vehicle Technology, \\ Beijing 100076, China; 15850577689@sina.cn \\ 3 Aviation Engineering College, Air Force Engineering University, Xi'an 710038, China \\ 4 School of Electronic Information, Jiangsu University of Science and Technology, Zhenjiang 212003, China \\ * Correspondence: wjy@njust.edu.cn
}

check for updates

Citation: Yin, H.; Yi, W.; Wu, J.; Wang, K.; Guan, J. Adaptive Fuzzy Neural Network PID Algorithm for BLDCM Speed Control System. Mathematics 2022, 10, 118. https:// doi.org/10.3390/math10010118

Academic Editor: Georgios Tsekouras

Received: 24 November 2021

Accepted: 27 December 2021

Published: 31 December 2021

Publisher's Note: MDPI stays neutral with regard to jurisdictional claims in published maps and institutional affiliations.

Copyright: (C) 2021 by the authors. Licensee MDPI, Basel, Switzerland. This article is an open access article distributed under the terms and conditions of the Creative Commons Attribution (CC BY) license (https:// creativecommons.org/licenses/by/ $4.0 /)$.

\begin{abstract}
Because of its simple structure, high efficiency, low noise, and high reliability, the brushless direct current motor (BLDCM) has an irreplaceable role compared with other types of motors in many aspects. The traditional proportional integral derivative (PID) control algorithm has been widely used in practical engineering because of its simple structure and convenient adjustment, but it has many shortcomings in control accuracy and other aspects. Therefore, in this paper, a fuzzy single neuron neural network (FSNNN) PID algorithm based on an automatic speed regulator (ASR) is designed and applied to a BLDCM control system. This paper introduces a BLDCM mathematical model and its control system and designs an FSNNN PID algorithm that takes speed deviation $e$ at different sampling times as inputs of a neural network to adjust the PID parameters, and then it uses a fuzzy system to adjust gain $K$ of the neural network. In addition, the frequency domain stability of a double closed loop PID control system is analyzed, and the control effect of traditional PID, fuzzy PID, and FSNNN PID algorithms are compared by setting different reference speeds, as well as the change rules of three-phase current, back electromotive force (EMF), electromagnetic torque, and rotor angle position. Finally, results show that a motor controlled by the FSNNN PID algorithm has certain superiority compared with traditional PID and fuzzy PID algorithms and also has better control effects.
\end{abstract}

Keywords: brushless direct current motor (BLDCM); automatic speed regulator (ASR); fuzzy single neuron neural network (FSNNN) algorithm; performance index

\section{Introduction}

The brushless direct current motor (BLDCM), also called a permanent magnet synchronous motor, is one of the motor types that is coming of age due to continuous improvement in high energy permanent magnet materials, power semiconductors, digital integrated circuits, and computer technology. BLDCM has received a great deal of attention in many applications such as electric automotive, aerospace, robotics, military, industrial control, and electric vehicles because it has many predominant features such as a simple structure, high efficiency, better reliability, less noise, and is free of maintenance over a wide range of speeds [1-4]. BLDCM is a device that can convert electrical energy into mechanical energy. The distinct feature of BLDCM is the adopting of electronic commutation instead of mechanical commutation of the traditional direct current (DC) motor. Thus, by eliminating the mechanical commutators and brushes, the problems of radio frequency interference and sparking are solved. In addition, BLDCM has trapezoidal electromotive force (EMF) and quasi-rectangular current waveforms. Three Hall sensors are usually used as position sensors to perform current commutations every 60 electrical degrees [5,6]. It is well known that up until now, the traditional proportional integral derivative (PID) controller has been 
the most widely used in practical engineering due to its simple control structure, ease of design, and inexpensive cost. However, the PID controller cannot yield a good control algorithm if the controlled object is highly nonlinear and uncertain [7]. Though there exists a model, BLDCM is also susceptible to un-modeled dynamics, parameter variations, uncertainties, and disturbances, such as the impact of electrical and mechanical disturbances in practical operation, which limits the application of control algorithms relying on the model [8].

In the last few years, a large number of contributions based on various advanced intelligent control strategies such as sliding-mode control [9,10], ant colony algorithm [11,12], genetic algorithm $[13,14]$, particle swarm optimization (PSO) algorithm [15,16], model reference adaptive control (MRAC) algorithm [17,18], fuzzy control [19,20], artificial neural network control algorithm [21,22], and so on, have been proposed to solve this problem. Among them, the fuzzy control algorithm is widely used in various control systems because it has the advantage of not needing to master the mathematical model of the controlled object but organizes the control decision table according to manual rules and then determines the size of the control amount. Fuzzy control has developed rapidly, and many experts and scholars have applied it in many aspects [23-26]. However, the establishment of fuzzy mathematics requires a great deal of control experience and has greater subjectivity. The inputs and outputs are inevitably affected by the limited scope of the universe and the division of fuzzy subsets, which leads to the slow response of fuzzy control. Furthermore, through adopting "if-then" control rules, there are some inconveniences in learning and adjusting control parameters, so the accuracy is generally not high. In order to solve these shortcomings of fuzzy control algorithms mentioned above, fuzzy control combined with other intelligence algorithms is used to improve the performance of the fuzzy controller. Among them, the neural network has strong advantages in adapting to complex environments and multi-objective control. The algorithm structure is simple and clear, and it does not depend on a mathematical model of the controlled object. With strong parallel computing, self-learning, self-organization, and self-adaptation ability, it can be used in control processes that are difficult or impossible to describe with mathematical models and control rules [27]. In 1943, psychologist Warren S. Mcculloch and mathematical logician Walter Pitts first proposed the concept of the artificial neural network and the mathematical model of artificial neurons, thus opening the era of artificial neural network research [28]. Then, American neuroscientist F. Rosenblatt proposed a machine that could simulate human's perception ability in 1958, which was called the "perceptron" artificial neural network [29]. In 1986, D. E. Rumelhart et al. restudied the BP artificial neural network algorithm, which overcame the weakness of early-rising neurons and provided a practical solution for learning, training, and implementation of the multilayer neural network [30]. In the following ten years, due to its shallow structure, easy over fitting, and slow parameter training speed, the once hot neural network gradually faded out of people's attention, until 2006, when G. E. Hinton and his student R. R. Salakhutdinov's research on neural networks set off an upsurge of deep learning in academia and industry, which opened the curtain of deep learning and marked the birth of deep learning [31]. So far, in the development of neural networks for nearly 80 years, with the rapid increase of computer processing speed and storage capacity, artificial neural network technology has been applied to all aspects of industrial life [32-35].

The fuzzy neural network PID algorithm makes use of advantages of both the learning capability of the neural network and the robustness of fuzzy logic control that compensates the disadvantages of modification of fuzzy rules or models. Chhipa et al. proposed an adaptive neuro-fuzzy inference system (ANFIS) maximum power point tracking (MPPT) controller for grid-connected doubly fed induction generator (DFIG)-based wind energy conversion systems (WECS). Then the controller's performance was tested under various wind speed circumstances and compared with the performance of a conventional proportional-integral MPPT controller. A simulation study showed that WECS can operate at its optimum power for the proposed controller's wide range of input wind speed [36]. 
In Reference [37], Qiao et al. investigated an adaptive fuzzy neural network control system for the multiobjective operation of a wastewater treatment process with standard effluent quality as well as low energy consumption. The performance comparison with other algorithms indicated that the proposed control system yielded better effluent qualities and lower average operation consumption. In Reference [38], Ali et al. was concerned with the problem of state estimation of Takagi-Sugeno (T-S) fuzzy delayed neural networks with Markovian jumping parameters via sampled-data control. Based on LyapunovKrasovskii stability theory and linear matrix inequality (LMI) formulation, a new set of delay-dependent conditions was developed to estimate the state variables of fuzzy neural networks through available output measurements, such that the error system was asymptotically stable. Numerical examples were given to illustrate the usefulness and effectiveness of the proposed results. In Reference [39], Guan et al. proposed a new fuzzy deep neural network architecture for lip image segmentation. A large number of lip image dataset experiments were carried out, and the results showed that the proposed method achieved state-of-the-art performance when compared with other algorithms. In Reference [40], S. Varela-Santos et al. described a new hybrid approach, based on modular artificial neural networks with fuzzy logic integration, for the diagnosis of pulmonary diseases such as pneumonia and lung nodules. The proposed approach achieved high classification accuracy after evaluating the neuro-fuzzy model with three large datasets of chest X-rays. Zhang et al. proposed a neural network-based fuzzy controller to attenuate the irregular wave-induced vibration of a steeljacket offshore platform, and it achieved better vibration-attenuating performance under uncertain control delay and random waves, when compared to existed optimal control laws and fuzzy controllers without neural networks [41].

In previous work, we proposed a fuzzy PI algorithm for BLDCM control systems, and results verified the superiority of the fuzzy PI algorithm for BLDCM double closed loop systems compared with traditional PID controls [42]. The establishment of fuzzy mathematics needs a lot of experience and strong subjectivity, therefore, in order to improve the shortcomings of fuzzy control, such as slow response speed and low control accuracy. This paper presents a FSNNN PID algorithm, which makes full use of the advantages of strong adaptive ability of fuzzy control, and the strong self-learning, self-organization, and parallel computing of neural networks. In addition, the FSNNN PID algorithm takes the speed deviation $e$ at different sampling times as the input of a neural network to adjust PID parameters, and fuzzy control is used to modify the output gain $K$ of the neural network online, which takes the speed deviation $e$ and deviation change rate $e c$ as the input and the gain adjustment coefficient $K^{\prime}$ as the output of fuzzy systems. Finally, the rest of this paper is structured as follows: Section 2 introduces the mathematical model of BLDCM. In Section 3, the FSNNN PID algorithm is designed and applied in the ASR of a BLDCM double closed loop control system. Section 4 introduces a motor control system, as well as the modulation mode of Mosfet and the relationship between Mosfet and Hall sensors. Section 5 analyzes the frequency domain stability of a double closed loop PID control system and the step response performance index of motor speed in the time domain, as well as the change rules of three-phase current, back EMF, electromagnetic torque, and rotor angle position. Conclusions are drawn in Section 6.

\section{Mathematical Model of BLDCM}

The phase voltage of three-phase A, B, and C winding in BLDCM is composed of resistance drop and induced EMF; an equivalent circuit of BLDCM is shown in Figure 1.

Take phase $\mathrm{A}$ as an example,

$$
U_{\mathrm{A}}=R_{\mathrm{A}} i_{\mathrm{A}}+e_{\psi \mathrm{A}} \text {, }
$$


where $U_{\mathrm{A}}$ is phase voltage, $R_{\mathrm{A}}$ is phase resistance, $i_{\mathrm{A}}$ is phase current, and $e_{\psi \mathrm{A}}$ is phaseinduced EMF; the winding-induced EMF is equal to the change rate of the flux $\psi_{\mathrm{A}}$, that is,

$$
e_{\psi_{\mathrm{A}}}=\frac{\mathrm{d} \psi_{\mathrm{A}}}{\mathrm{d} t}
$$

Furthermore, the flux $\psi_{\mathrm{A}}$ is given as

$$
\psi_{\mathrm{A}}=L_{\mathrm{A}} i_{\mathrm{A}}+M_{\mathrm{AB}} i_{\mathrm{B}}+M_{\mathrm{AC}} i_{\mathrm{C}}+\psi_{\mathrm{pm}}(\theta),
$$

where $L_{\mathrm{A}}$ is the self-inductance, $M_{\mathrm{AB}}$ and $M_{\mathrm{AC}}$ are the mutual inductance of phase A with phase $B$ and phase $C$, respectively; $i_{B}$ and $i_{C}$ are the phase $B$ and $C$ currents, respectively; $\psi_{\mathrm{pm}}(\theta)$ is the permanent magnet (PM) flux linkage of phase $\mathrm{A}$; and $\theta$ is the position angle of the rotor, the angle between the rotor $d$-axis and the axis of phase A.

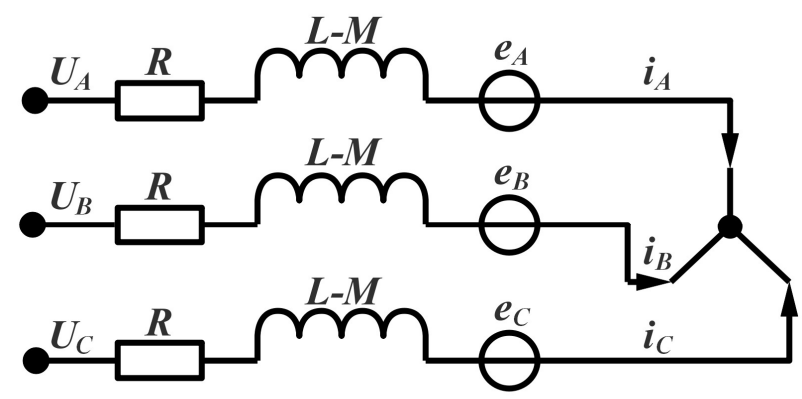

Figure 1. Equivalent circuit of BLDCM.

When the rotor position is $\alpha$, the PM flux of phase $\mathrm{A}$ is

$$
\begin{gathered}
\psi_{\mathrm{pm}}(\alpha)=N \phi_{\mathrm{pm}}(\alpha) \\
\phi_{\mathrm{pm}}(\alpha)=\int_{-\frac{\pi}{2}+\alpha}^{\frac{\pi}{2}+\alpha} B(\theta) \cdot S \mathrm{~d} \theta,
\end{gathered}
$$

where $\phi_{\mathrm{pm}}(\alpha)$ is PM flux of phase A when the rotor position angle is $\alpha, B(\theta)$ is PM rotor radial flux density in the air gap, which is in a trapezoidal distribution along $\theta, N$ is turns of windings, and $S$ is product of rotor radius and effective length of conductors.

Substituting Equations (2)-(5) into Equation (1), the following can be obtained:

$$
\begin{aligned}
U_{\mathrm{A}} & =R_{\mathrm{A}} \cdot i_{\mathrm{A}}+\frac{\mathrm{d}}{\mathrm{d} t}\left(L_{\mathrm{A}} i_{\mathrm{A}}+M_{\mathrm{AB}} i_{\mathrm{B}}+M_{\mathrm{AC}} i_{\mathrm{C}}+\psi_{\mathrm{pm}}\right) \\
& =R_{\mathrm{A}} \cdot i_{\mathrm{A}}+\frac{\mathrm{d}}{\mathrm{d} t}\left(L_{\mathrm{A}} i_{\mathrm{A}}+M_{\mathrm{AB}} i_{\mathrm{B}}+M_{\mathrm{AC}} i_{\mathrm{C}}\right)+\frac{\mathrm{d}}{\mathrm{d} t}\left[N S \int_{-\frac{\pi}{2}+\theta}^{\frac{\pi}{2}+\theta} B(x) \mathrm{d} x\right] \\
& =R_{\mathrm{A}} \cdot i_{\mathrm{A}}+\frac{\mathrm{d}}{\mathrm{d} t}\left(L_{\mathrm{A}} i_{\mathrm{A}}+M_{\mathrm{AB}} i_{\mathrm{B}}+M_{\mathrm{AC}} i_{\mathrm{C}}\right)+e_{\mathrm{A}}
\end{aligned}
$$

where $e_{\mathrm{A}}$ is the back-EMF of phase A. Further, as the three-phase stator windings are symmetrical, the self-inductances will be equal, and so as the mutual inductance, that is $L_{\mathrm{A}}=L_{\mathrm{B}}=L_{\mathrm{C}}=L, M_{\mathrm{AB}}=M_{\mathrm{BA}}=M_{\mathrm{BC}}=M_{\mathrm{CB}}=M_{\mathrm{AC}}=M_{\mathrm{CA}}=M$. Substituting them into Equation (6), the following can be obtained:

$$
U_{\mathrm{A}}=R_{\mathrm{A}} \cdot i_{\mathrm{A}}+L \frac{\mathrm{d} i_{\mathrm{A}}}{\mathrm{d} t}+M \frac{\mathrm{d} i_{\mathrm{B}}}{\mathrm{d} t}+M \frac{\mathrm{d} i_{\mathrm{C}}}{\mathrm{d} t}+e_{\mathrm{A}}
$$

Furthermore, $e_{\mathrm{A}}$ is rotating back EMF that is produced by the winding flux linkage caused by the rotating rotor; it also can be expressed as

$$
e_{\mathrm{A}}=2 N S \omega B_{\mathrm{m}} f_{\mathrm{A}}(\theta)=\omega \psi_{\mathrm{m}} f_{\mathrm{A}}(\theta) .
$$

$\omega$ is the electrical angular speed of motor, $B_{\mathrm{m}}$ is the maximum value of PM density distribution in air gap, $\psi_{\mathrm{m}}$ is the maximum value of PM flux linkage of each winding, and 
$f_{\mathrm{A}}(\theta)$ is back EMF waveform function of phase A. Note that the $f_{\mathrm{A}}(\theta)$ has a trapezoidal distribution with the rotor position, and its maximum and minimum values are, respectively, 1 and -1 . That is,

$$
f_{\mathrm{A}}(\theta)=\left\{\begin{array}{cl}
(6 / \pi) \theta & (0<\theta \leq \pi / 6) \\
1 & (\pi / 6<\theta \leq 5 \pi / 6) \\
-(6 / \pi) \theta+6 & (5 \pi / 6<\theta \leq 7 \pi / 6) \\
-1 & (7 \pi / 6<\theta \leq 11 \pi / 6) \\
(6 / \pi) \theta-12 & (11 \pi / 6<\theta \leq 2 \pi)
\end{array} .\right.
$$

As for the three phase symmetrical windings, $f_{\mathrm{B}}(\theta)=f_{\mathrm{A}}(\theta-2 \pi / 3)$, and $f_{\mathrm{C}}(\theta)=f_{\mathrm{A}}(\theta+$ $2 \pi / 3)$, and the curve of $f_{\mathrm{A}}(\theta)$ is shown in Figure 2 .

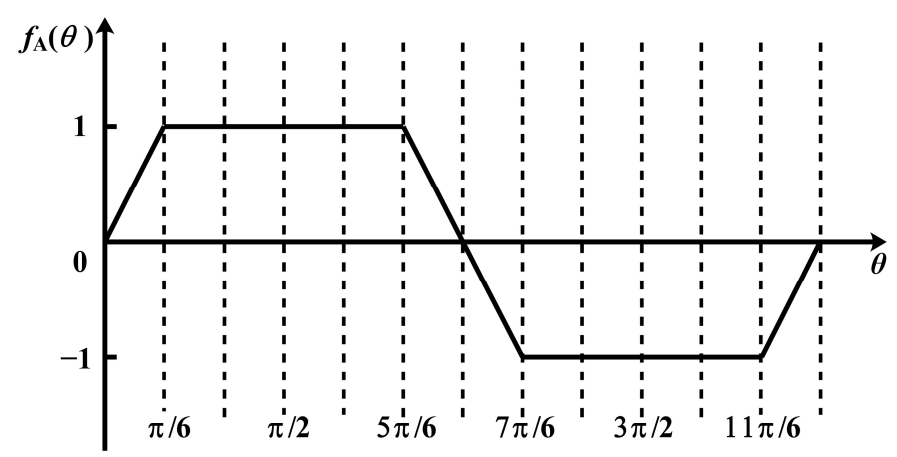

Figure 2. Back EMF waveform function of phase A.

As the currents of the three phase satisfy $i_{\mathrm{A}}+i_{\mathrm{B}}+i_{\mathrm{C}}=0$, and $R_{\mathrm{A}}=R_{\mathrm{B}}=R_{\mathrm{C}}=R$, the mathematical model of the BLDCM phase voltage equation can thus be expressed as

$$
\begin{aligned}
& U_{\mathrm{A}}=R \cdot i_{\mathrm{A}}+(L-M) \cdot \frac{\mathrm{d} i_{\mathrm{A}}}{\mathrm{d} t}+e_{\mathrm{A}} \\
& U_{\mathrm{B}}=R \cdot i_{\mathrm{B}}+(L-M) \cdot \frac{\mathrm{d} B_{\mathrm{B}}}{\mathrm{dt}}+e_{\mathrm{B}} \\
& U_{\mathrm{C}}=R \cdot i_{\mathrm{C}}+(L-M) \cdot \frac{\mathrm{d} i_{\mathrm{C}}}{\mathrm{d} t}+e_{\mathrm{C}}
\end{aligned}
$$

When the motor is operating, power from the source is absorbed. Due to the influence of nonlinear factors such as clearance, friction, and elastic deformation on the rotor, most of the power is transferred through the air gap to the rotor by the torque effect. However, only when the armature voltage reaches a certain value will the rotor rotate, that is, there is a dead zone. When armature voltage exceeds a certain value, motor speed will not increase, and saturation will occur. In addition, less of the power is turned into copper loss and iron loss is the uncertainties of the system. The power transferred to the rotor, which is called the electromagnetic power, equals the sum of the product of current and back EMF of the three phases. That is,

$$
P_{\mathrm{e}}=e_{\mathrm{A}} \cdot i_{\mathrm{A}}+e_{\mathrm{B}} \cdot i_{\mathrm{B}}+e_{\mathrm{C}} \cdot i_{\mathrm{C}}
$$

Ignoring the mechanical loss and stray loss, the electromagnetic power is totally turned into kinetic energy; so,

$$
P_{\mathrm{e}}=T_{\mathrm{e}} \cdot \Omega
$$

Hence,

$$
T_{\mathrm{e}}=\left(e_{\mathrm{A}} \cdot i_{\mathrm{A}}+e_{\mathrm{B}} \cdot i_{\mathrm{B}}+e_{\mathrm{C}} \cdot i_{\mathrm{C}}\right) / \Omega
$$

where $T_{\mathrm{e}}$ is electromagnetic torque, and $\Omega$ is angular velocity of rotation.

The motor motion equation is as follows:

$$
T_{\mathrm{e}}-T_{\mathrm{L}}=J \frac{\mathrm{d} \Omega}{\mathrm{d} t}+B_{\mathrm{v}} \Omega
$$


where $T_{\mathrm{L}}$ is the load torque, $J$ is the rotor moment of inertia, and $B_{\mathrm{V}}$ is the viscous friction coefficient. Thus, the above equations constitute the differential mathematical model of BLDCM.

\section{FSNNN PID Algorithm}

The FSNNN PID algorithm is based on the fusion of fuzzy control and neural network; it can not only give full play to the advantages of fuzzy control, which does not depend on the mathematical model of the controlled object and has strong robustness, but also carries forward the advantages of the neural network that can approximate any nonlinear function, namely a simple structure and clear learning algorithm. By learning the neural network itself, the PID parameters under a certain optimal control law can be found. However, the neural network is usually composed of multi-layers and multi neurons, with complex structures and long weight training times, which are not conducive to real-time control. Each neuron in a neural network has its own ability of self-learning and selfadaptive and can approximate any function. Moreover, the single neuron algorithm has the advantages of simple structure, less computational cost, short weight learning time, and easy implementation. The output gain $K$ of a single neuron neural network has a great influence on the stability and convergence speed of the controller. In order to improve control quality, a fuzzy control algorithm is used to adjust output gain $K$ in real time. The structure of the FSNNN PID controller is shown in Figure 3.

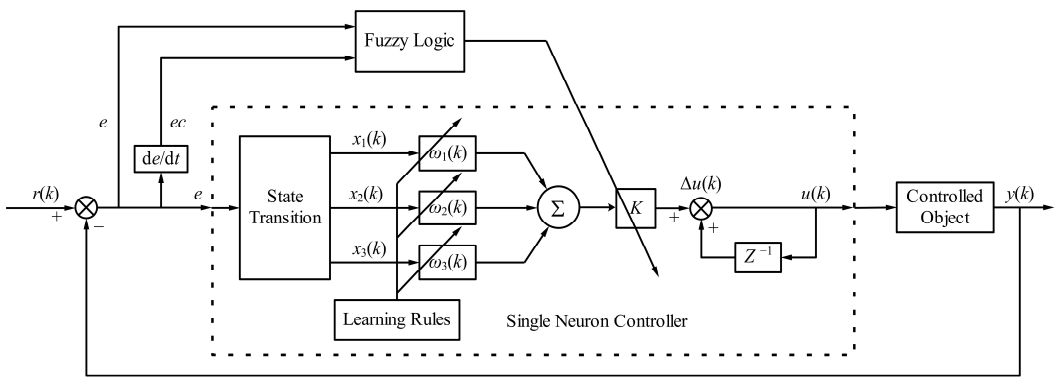

Figure 3. The structure of FSNNN PID control algorithm.

\subsection{SNNN PID Algorithm}

PID control is the earliest developed control algorithm [43], and its advantages are simple structure, better adaptability, and high reliability. Furthermore, its mathematical model is as follows:

$$
\begin{aligned}
& e(k)=r(k)-y(k) \\
& u(k)=\Delta u(k)+u(k-1) \\
& \Delta u(k)=K_{\mathrm{p}}(e(k)-e(k-1))+K_{\mathrm{i}} e(k)+K_{\mathrm{d}}(e(k)-2 e(k-1)+e(k-2))
\end{aligned}
$$

where $r(k)$ is the reference setting value, $y(k)$ is actual output value of the system, and $e(k)$ is the deviation between the above two; $u(k)$ represents the output value at current sampling time of the PID controller, $u(k-1)$ is the output value at a previous sampling time, and $\Delta u(k)$ is the deviation between above two. Similarly, $e(k-1)$ is the deviation $e(k)$ at a previous sampling time, and $e(k-2)$ is the deviation at the previous two sampling times. $K_{\mathrm{p}}$ is the proportional coefficient, $K_{\mathrm{i}}$ is the integral coefficient, and $K_{\mathrm{d}}$ is the differential coefficient of the PID control algorithm.

A single neuron neural network (SNNN) PID algorithm is composed of single neuron and traditional PID control. In essence, it takes the proportional $P$, integral $I$, and derivative $D$ as the input weights of neurons, and simplifies the hidden layer into a variable coefficient, compound, and adaptive neural network controller. The output value $u(k)$ of the system is calculated as follows:

$$
u(k)=u(k-1)+K \sum_{i=1}^{3} \omega_{i}^{\prime}(k) x_{i}(k)
$$


where $K(K>0)$ is the gain coefficient of the neuron, $\omega_{i}{ }^{\prime}(k)$ is normalized weight, and $x_{i}(k)$ is state transition quantity of $e(k)$; the calculation method of $x_{i}(k)$ is as follows:

$$
\begin{aligned}
& x_{1}(k)=e(k) \\
& x_{2}(k)=\Delta e(k)=e(k)-e(k-1) \\
& x_{3}(k)=\Delta^{2} e(k)=e(k)-2 e(k-1)+e(k-2)
\end{aligned}
$$

Mathematical expression of the normalized weight $\omega_{i}{ }^{\prime}(k)$ is as follows:

$$
\omega_{i}^{\prime}(k)=\frac{\omega_{i}(k)}{\sum_{i=1}^{3}\left|\omega_{i}(k)\right|}
$$

The normalized weight $\omega_{i}{ }^{\prime}(k)$ of single neuron controller can be adjusted online to realize the function of self-adaptive and self-organization. The learning algorithm of $\omega_{i}{ }^{\prime}(k)$ mainly includes an unsupervised Hebb learning algorithm, supervised Delta learning algorithm, and supervised Hebb learning algorithm. Among them, the supervised Hebb learning algorithm takes into account the relationship between weight coefficient and input, output, and output deviation of neurons, which has better control performance than the other two learning algorithms. The supervised Hebb learning algorithm is as follows:

$$
\begin{aligned}
& \omega_{1}(k)=\omega_{1}(k-1)+\eta_{\mathrm{P}} z(k) u(k) x_{1}(k) \\
& \omega_{2}(k)=\omega_{2}(k-1)+\eta_{\mathrm{I}} z(k) u(k) x_{2}(k) \\
& \omega_{3}(k)=\omega_{3}(k-1)+\eta_{\mathrm{D}} z(k) u(k) x_{3}(k)
\end{aligned}
$$

Practice shows that the online learning correction of PID parameters is mainly related to $e(k)$ and $\Delta e(k)$. Based on this, the weight coefficient learning correction part of the SNNN PID control algorithm can be improved, and the improved algorithm is as follows:

$$
\begin{aligned}
& \omega_{1}(k)=\omega_{1}(k-1)+\eta_{\mathrm{P}} z(k) u(k)(e(k)+\Delta e(k)) \\
& \omega_{2}(k)=\omega_{2}(k-1)+\eta_{\mathrm{I}} z(k) u(k)(e(k)+\Delta e(k)) \\
& \omega_{3}(k)=\omega_{3}(k-1)+\eta_{\mathrm{D}} z(k) u(k)(e(k)+\Delta e(k))
\end{aligned}
$$

where $z(k)$ is the performance index or progressive signal; taking $z(k)=e(k), \eta_{\mathrm{P}}, \eta_{\mathrm{I}}$, and $\eta_{\mathrm{D}}$ are the learning rates of PID coefficients, respectively, the different learning rates of which are used to adjust different weights. If system response time is too long, $\eta_{\mathrm{P}}$ and $\eta_{\mathrm{I}}$ will be increased; if overshoot decreases rapidly to a stable value and then rises, and steady-state time is too long, the integral $I$ will be reduced. For a large delay system, in order to reduce overshoot, $\eta_{\mathrm{P}}$ and $\eta_{\mathrm{D}}$ can be appropriately larger, and if system transition time is too long, $\eta_{\mathrm{I}}$ will be increased.

It is important to choose an appropriate gain $K$ of the SNNN algorithm. The larger $K$ is, the better convergence of system is, but it will lead to large overshoot and even make the system unstable. When the time delay of the controlled object increases, gain $K$ must decrease to ensure stability. However, if gain $K$ is small, the rapidity of the system will become worse. In order to realize online self-tuning of gain $K$ and improve control quality, a fuzzy control algorithm is designed to improve gain $K$ in this paper. Let $K=K_{0}+K^{\prime}, K_{0}$ is the initial value of $K$, and $K^{\prime}$ is adjusted online according to the fuzzy control algorithm.

\subsection{Fuzzy Control Adjust Gain K'}

The design process of the fuzzy control algorithm mainly includes fuzzification, establishment of fuzzy rules, fuzzy reasoning, and defuzzification. First of all, triangle and Gauss type membership functions are selected to fuzzy input variables, and the fuzzy universe is $(-6,6)$. It is the key of fuzzy controller to determine appropriate fuzzy rules to make the system achieve expected dynamic and static characteristics. Table 1 shows the fuzzy rules between $e, e c$, and $K^{\prime}$, and the fuzzy subsets of input and output linguistic variables are Negative Big, Negative Middle, Negative Small, Zero, Positive Small, Positive 
Middle, and Positive Big, represented by NB, NM, NS, ZO, PS, PM, and PB, respectively. Figure 4 shows the output space surface of the gain adjustment coefficient $K^{\prime}$.

Table 1. Fuzzy rules.

\begin{tabular}{|c|c|c|c|c|c|c|c|}
\hline$K^{\prime}$ & & & & $e$ & & & \\
\hline$e c$ & PB & $\mathbf{P M}$ & PS & ZO & NS & NM & NB \\
\hline PB & NB & NB & NM & NM & NS & NS & $\mathrm{ZO}$ \\
\hline PM & NB & NM & NM & NS & NS & $\mathrm{ZO}$ & PS \\
\hline PS & NM & NM & NS & $\mathrm{ZO}$ & $\mathrm{ZO}$ & PS & PS \\
\hline $\mathrm{ZO}$ & NS & NS & $\mathrm{ZO}$ & $\mathrm{ZO}$ & PS & $\mathrm{PM}$ & PM \\
\hline NS & NM & $\mathrm{ZO}$ & $\mathrm{ZO}$ & PS & PS & $\mathrm{PM}$ & PB \\
\hline NM & NS & $\mathrm{ZO}$ & PS & PS & PM & PM & PB \\
\hline NB & $\mathrm{ZO}$ & PS & PS & PM & PM & PB & PB \\
\hline
\end{tabular}

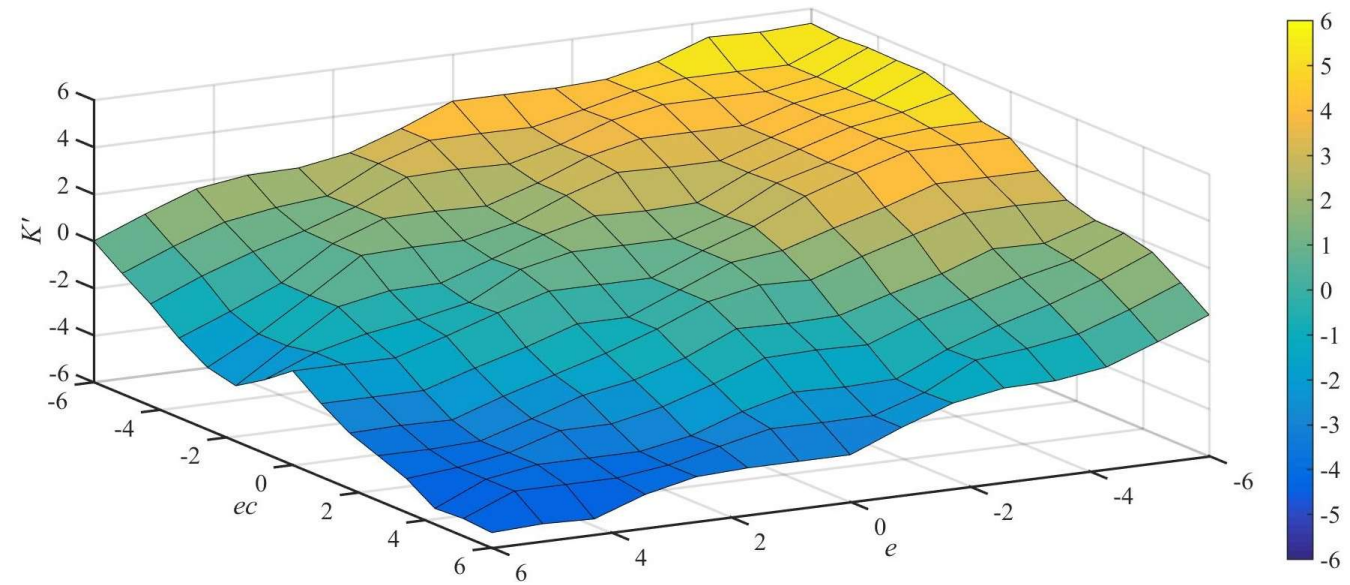

Figure 4. $K^{\prime}$ output space surface.

In this paper, the "if-then" min-max mamdani reasoning method of multi-inputs and single output is used for fuzzy reasoning. The general form of such rules is as follows:

Premise 1 ,

If $A$ and $B$, then $C$,

Premise 2,

Now $A^{\prime}$ and $B^{\prime}$,

Conclusion,

$$
\begin{aligned}
C^{\prime} & =\left(A^{\prime} \cap B^{\prime}\right) \circ[(A \cap B) \rightarrow C] \\
& =\left[A^{\prime} \circ(A \rightarrow C)\right] \cap\left[B^{\prime} \circ(B \rightarrow C)\right]
\end{aligned}
$$

where $A, B$, and $C$ are the fuzzy sets; $A^{\prime}, B^{\prime}$, and $C^{\prime}$ are corresponding inverse matrix; $\circ$ is max operation; $\rightarrow$ is the min operation; and $\cap$ is the and operation.

The process of converting a fuzzy amount into an accurate quantity is called defuzzification, and this paper uses the centroid method to solve the defuzzification operation. From this, we can obtain the accurate quantity $K^{\prime}$ of fuzzy logic controller, which is substituted into the following equation:

$$
K=K_{0}+\{E, E C\}_{K^{\prime}}
$$

where $K_{0}$ is the initial values of $K$, and $\{E, E C\}_{K^{\prime}}$ represents the accurate quantity after defuzzification.

\section{BLDCM Control System}

To verify the validity of the proposed method, in this paper, a double closed loop control pattern is built for a BLDCM system. In addition, the FSNNN PID algorithm is 
introduced into ASR, and the topological structure of the system is shown in Figure 5. Among them, $n^{*}$ is the set reference speed value, $n$ is actual speed, $i^{*}$ is the reference current value output by ASR, and $i$ is actual current. And automatic speed regulator (ACR) needs to have fast tracking ability, and the PID controller can limit the maximum current, so that the system has enough acceleration torque in starting and can ensure the steady state after reaching a stable speed. Furthermore, the main function of ASR is to enhance the system's ability to resist load disturbance, restrain speed fluctuation, and ensure the system's static and dynamic tracking performance, which is directly related to the stability and high-performance operation of BLDCM. ASR and ACR are connected in series, the output of ASR is used as the current given signal of ACR, and the output of ACR is used as the PWM control voltage of the drive circuit. The parameters of BLDCM are listed in Table 2.

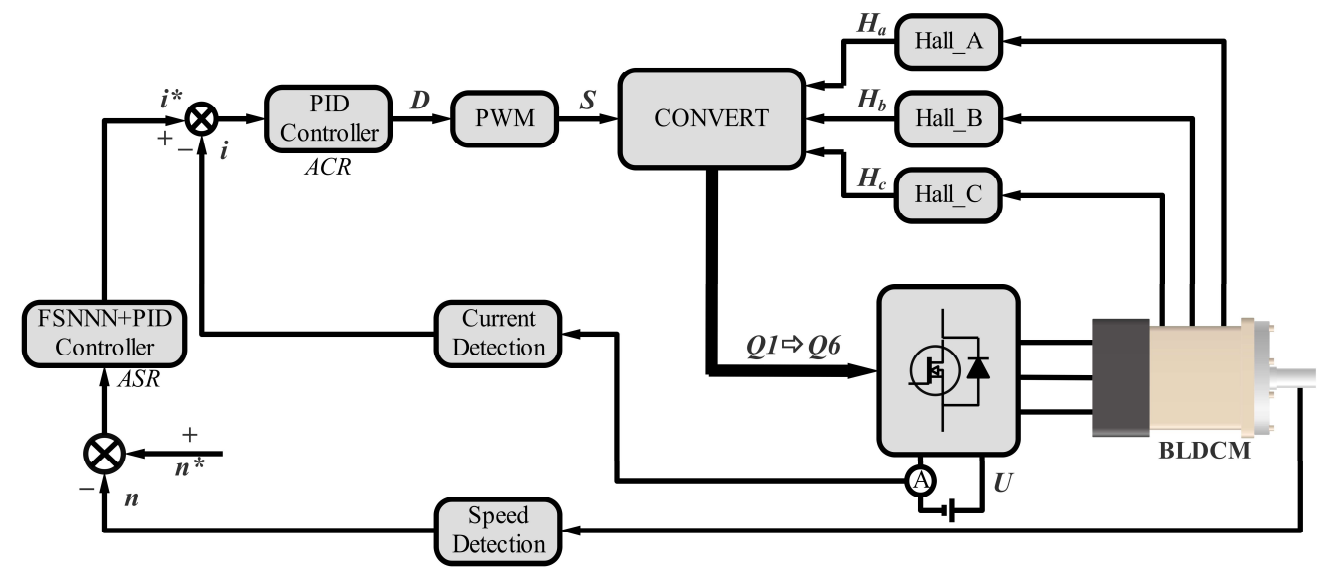

Figure 5. Overall control structure of BLDCM.

Table 2. BLDCM parameters.

\begin{tabular}{cccc}
\hline Parameters & Symbol & Value & Unit \\
\hline Rated voltage & $U_{\mathrm{N}}$ & 24 & $\mathrm{~V}$ \\
Rated current & $I_{\mathrm{N}}$ & 12.5 & $\mathrm{~A}$ \\
Rated load & $T_{\mathrm{N}}$ & 311 & $\mathrm{mN} \cdot \mathrm{m}$ \\
Phase resistance & $R$ & 0.0715 & $\Omega$ \\
Phase inductance & $L$ & 0.02825 & $\mathrm{mH}$ \\
PWM frequency & $f$ & 10 & $\mathrm{kHz}$ \\
Pairs of poles & $p$ & 1 & - \\
\hline
\end{tabular}

The switching commutation sequence of Mosfet in Figure 5, "CONVERT", is shown in Figure 6 below, specifically $\mathrm{A}+/ \mathrm{B}-, \mathrm{A}+/ \mathrm{C}-, \mathrm{B}+/ \mathrm{C}-, \mathrm{B}+\mathrm{A}-, \mathrm{C}+/ \mathrm{A}-$, and $\mathrm{C}+/ \mathrm{B}-$; the red line is the topology of current flow at a certain time. Furthermore, the Hall sensor signal and corresponding Mosfet switching state are shown in Table 3.

Table 3. Correspondence between Hall sensors and Mosfet switch states.

\begin{tabular}{ccccccccc}
\hline Hall_A & Hall_B & Hall_C & A+ & A- & B+ & B- & C+ & C- \\
\hline 1 & 0 & 1 & PWM & $\times$ & $\times$ & ON & $\times$ & $\times$ \\
0 & 0 & 1 & PWM & $\times$ & $\times$ & $\times$ & $\times$ & ON \\
0 & 1 & 1 & $\times$ & $\times$ & PWM & $\times$ & $\times$ & ON \\
0 & 1 & 0 & $\times$ & ON & PWM & $\times$ & $\times$ & $\times$ \\
1 & 1 & 0 & $\times$ & ON & $\times$ & $\times$ & PWM & $\times$ \\
1 & 0 & 0 & $\times$ & $\times$ & $\times$ & ON & PWM & $\times$ \\
\hline
\end{tabular}




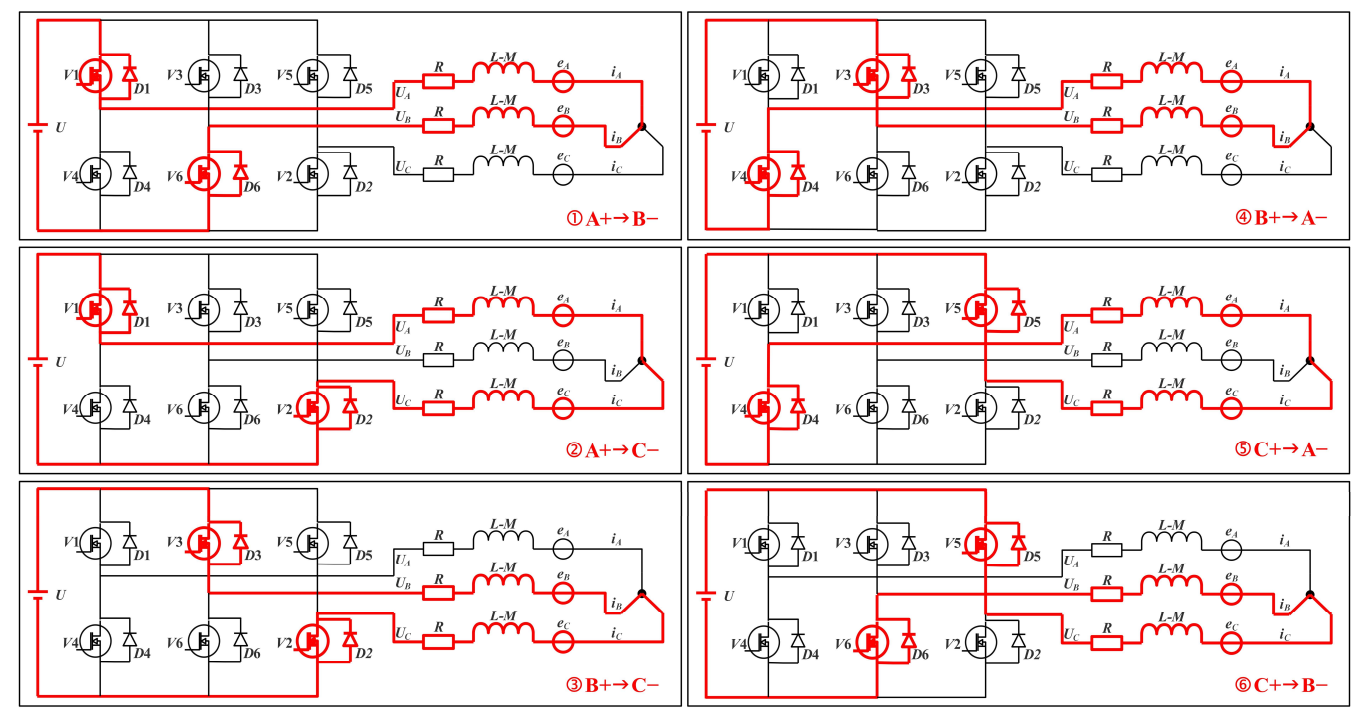

Figure 6. Logical commutation sequence of Mosfet.

In this paper, we adopted the H_PWM-L_ON modulation mode, that is, the Mosfet of the upper bridge arm is modulated by the PWM signal, and the Mosfet of the lower bridge arm remains constantly on. The switching state of Mosfet under the control of BLDCM using the FSNNN PID algorithm is shown in Figure 7; it is clear from the figure that during the on-time of Mosfet, V1, V3, and V5 are modulated by the PWM signal, and V4, V6, and $\mathrm{V} 2$ remain constant.
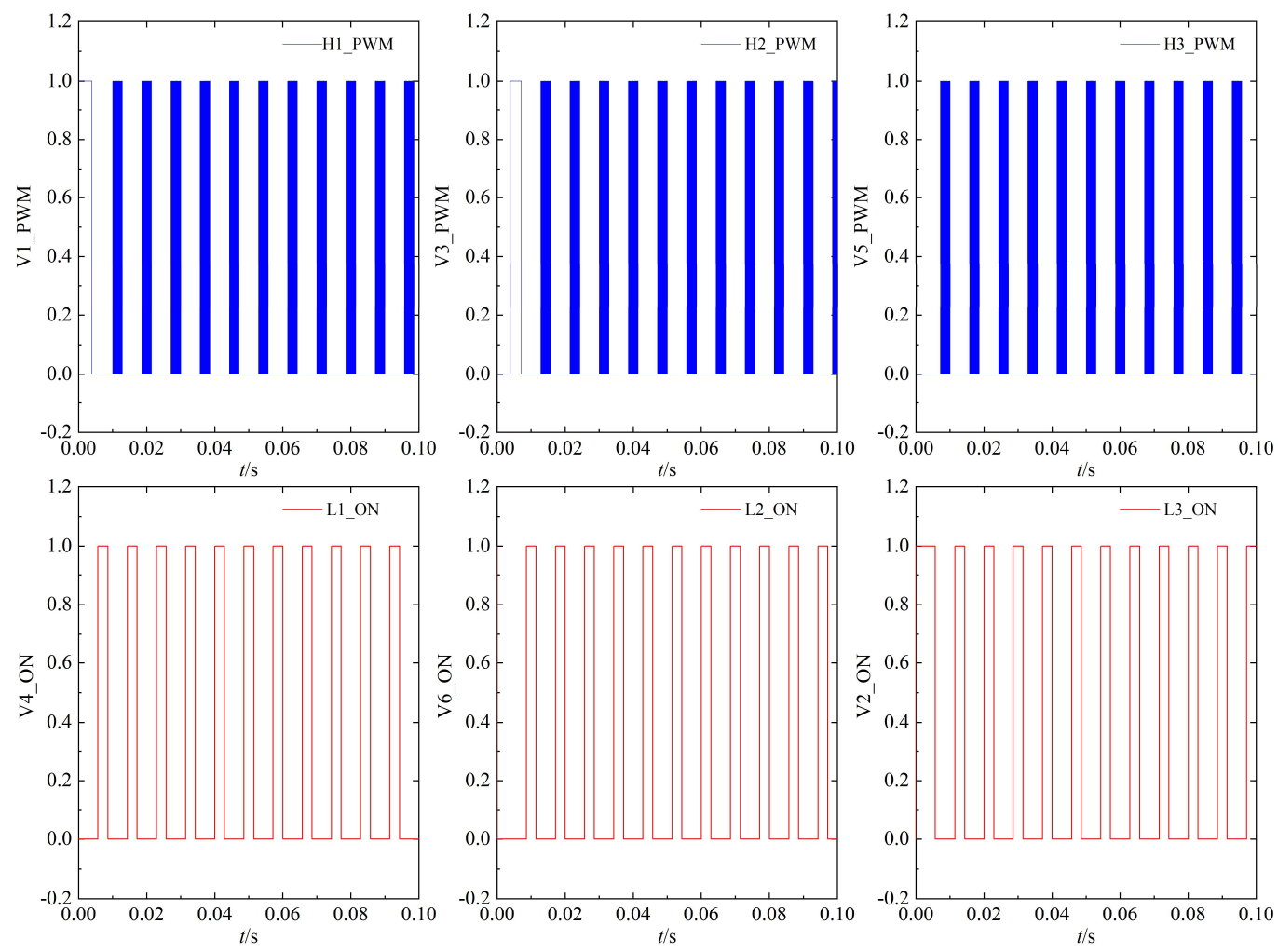

Figure 7. Logical state of Mosfet under FSNNN PID algorithm. 


\section{Results, Analysis, and Discussion}

\subsection{Frequency Domain Stability Analysis of Motor Double Closed Loop PID Control System}

The transfer function of the motor is significant for performance analysis and control system design; thus, the mathematical model of BLDCM in differential form expressed as the transfer function after Laplace transform is

$$
\begin{aligned}
\Omega(s) & =\frac{K_{\mathrm{T}} U_{\mathrm{d}}(s)}{L J s^{2}+\left(R J+L B_{\mathrm{V}}\right) s+\left(R B_{\mathrm{V}}+k_{\mathrm{e}} K_{\mathrm{T}}\right)} \\
& -\frac{(R+L s) T_{\mathrm{L}}(s)}{L J s^{2}+\left(R J+L B_{\mathrm{v}}\right) s+\left(R B_{\mathrm{V}}+k_{\mathrm{e}} K_{\mathrm{T}}\right)}
\end{aligned}
$$

where, $s$ is the Laplace operator, $\Omega(s)$ is angular velocity after Laplace transformation, $U_{\mathrm{d}}$ is DC bus voltage, $K_{\mathrm{T}}$ is torque coefficient, and $k_{\mathrm{e}}$ is back EMF coefficient; its control system structure is shown in Figure 8.

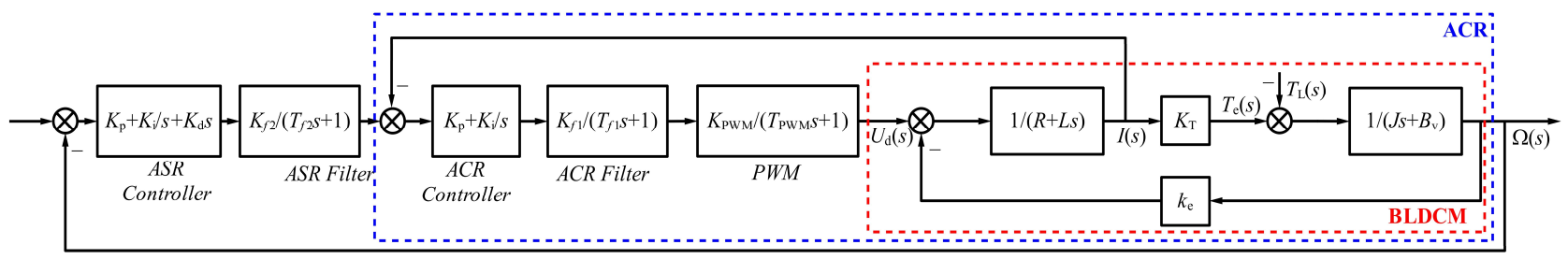

Figure 8. BLDCM control system transfer function structure.

The mathematical model based on the transfer function is widely used in the field of automatic control, and stability is the key issue in control system analysis and design; thus, it is important to analyze the stability of the motor control system in the frequency domain. Firstly, the stability of ACR in the BLDCM control system is analyzed; Figure 9 shows the Bode diagram in the frequency domain of the system, and it can be concluded that the amplitude margin of the ACR closed loop system stable point is $52.5 \mathrm{~dB}$ and the phase margin is $93.9^{\circ}$. Figure 10 shows the root trajectory of the system, in which red $\times$ represents the poles and blue $\bigcirc$ is the zeros; it can be seen that both the poles and zeros are located on the left half plane of imaginary axis, which proves the stability of the ACR loop. Figure 11 is the Nyquist diagram; it can be seen that the curve does not pass through the point $(-1,0)$, so the closed loop system is stable.

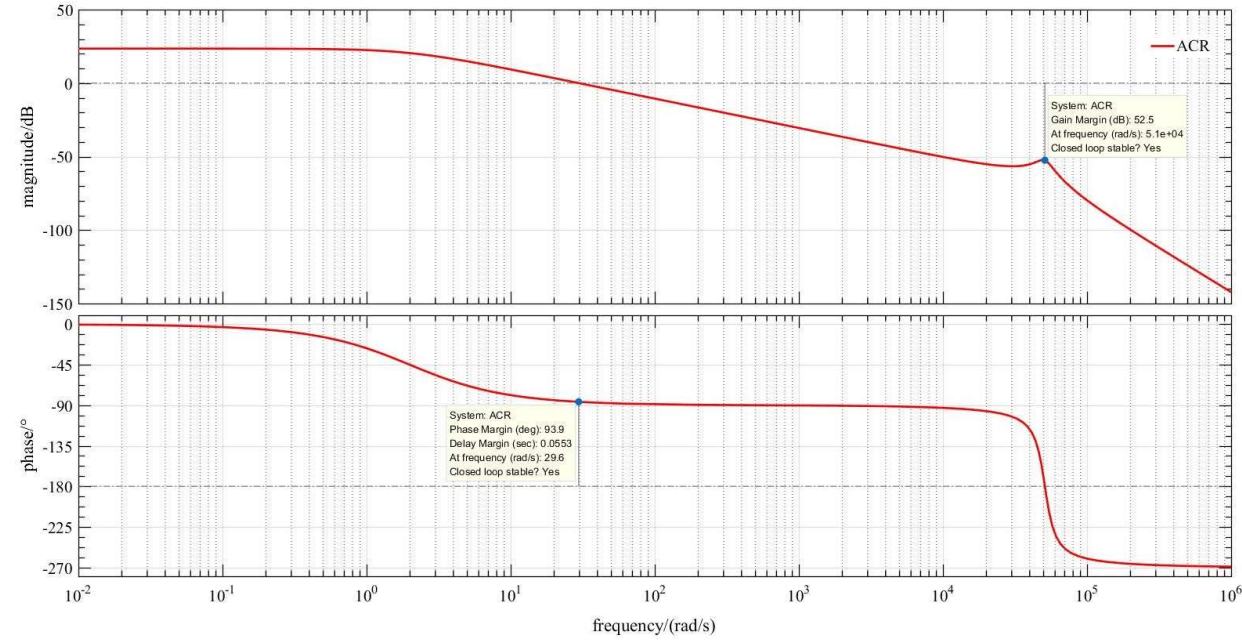

Figure 9. Bode diagram of ACR control system.

Then, the frequency domain stability of the motor double closed loop control system is analyzed. From the Bode diagram in Figure 12, it can be concluded that the amplitude margin is $91.9 \mathrm{~dB}$ and phase margin is $96.4^{\circ}$. Furthermore, the poles and zeros in the root 
trajectory of Figure 13 are all located on the left half plane of the imaginary axis. The Nyquist diagram in Figure 14 shows that the curve does not pass through the point $(-1,0)$, which also proves the stability of the system.

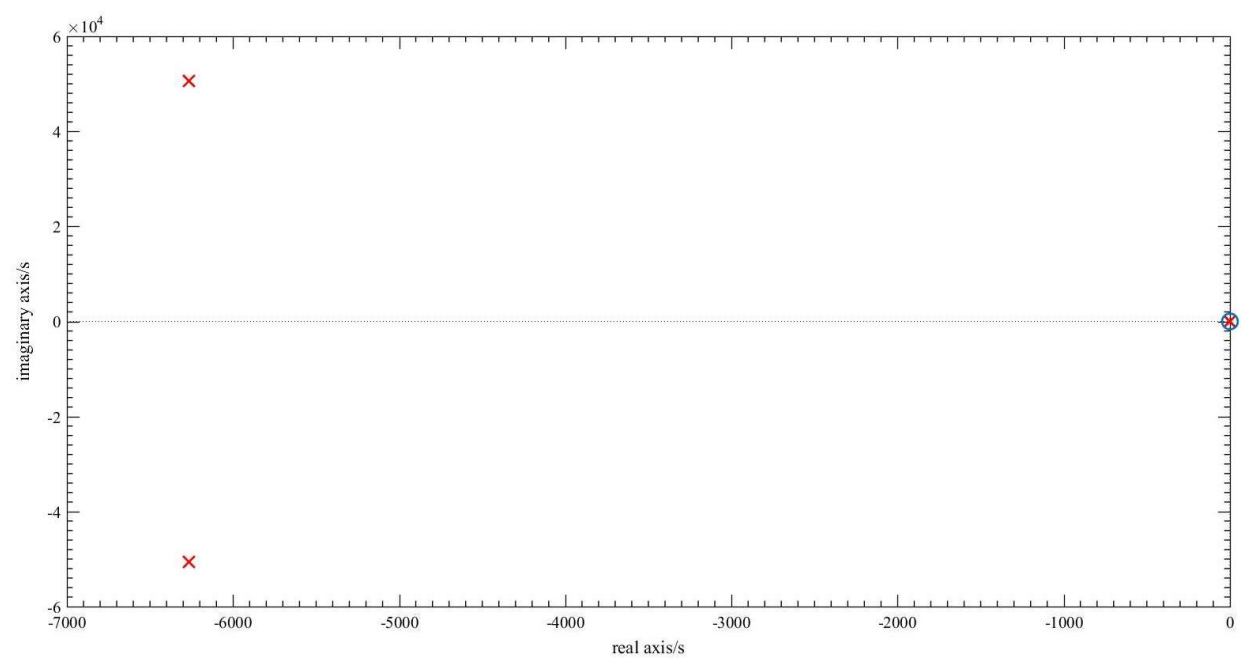

Figure 10. Root trajectory of ACR control system.

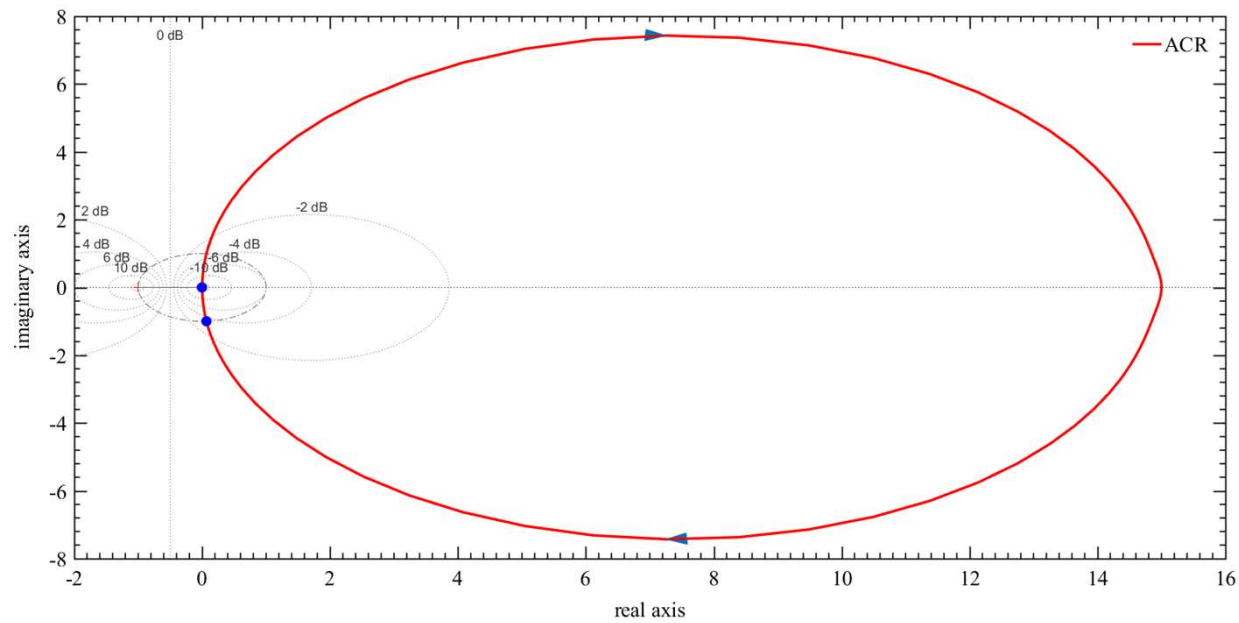

Figure 11. Nyquist diagram of ACR control system.

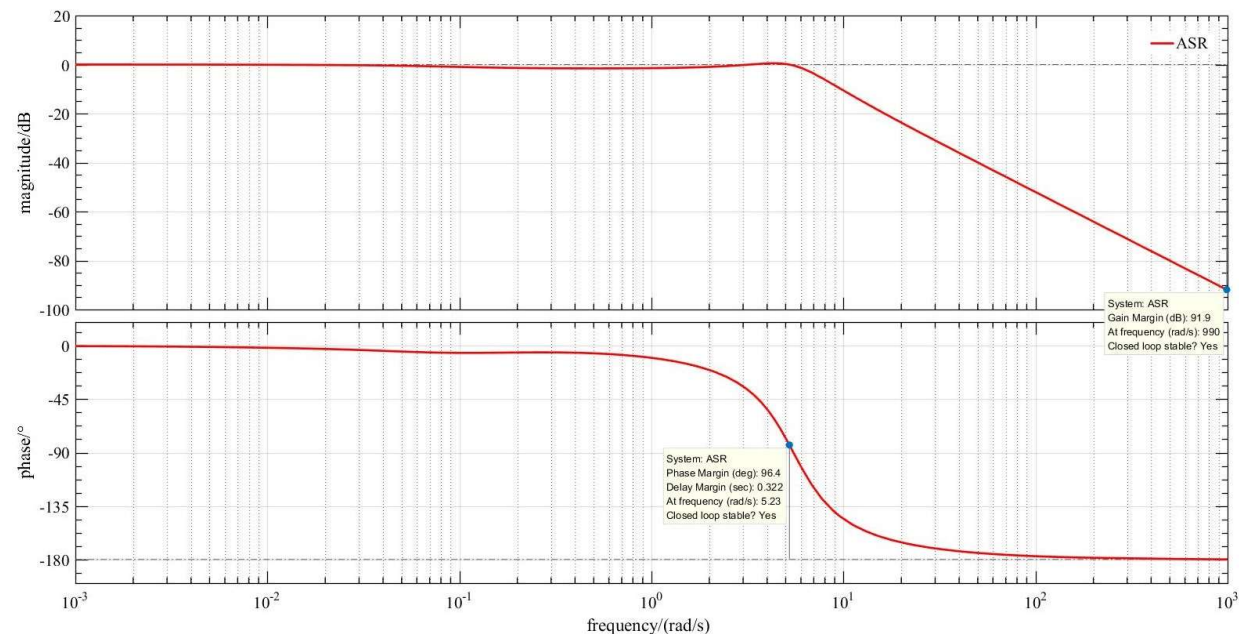

Figure 12. Bode diagram of double closed-loop control system. 


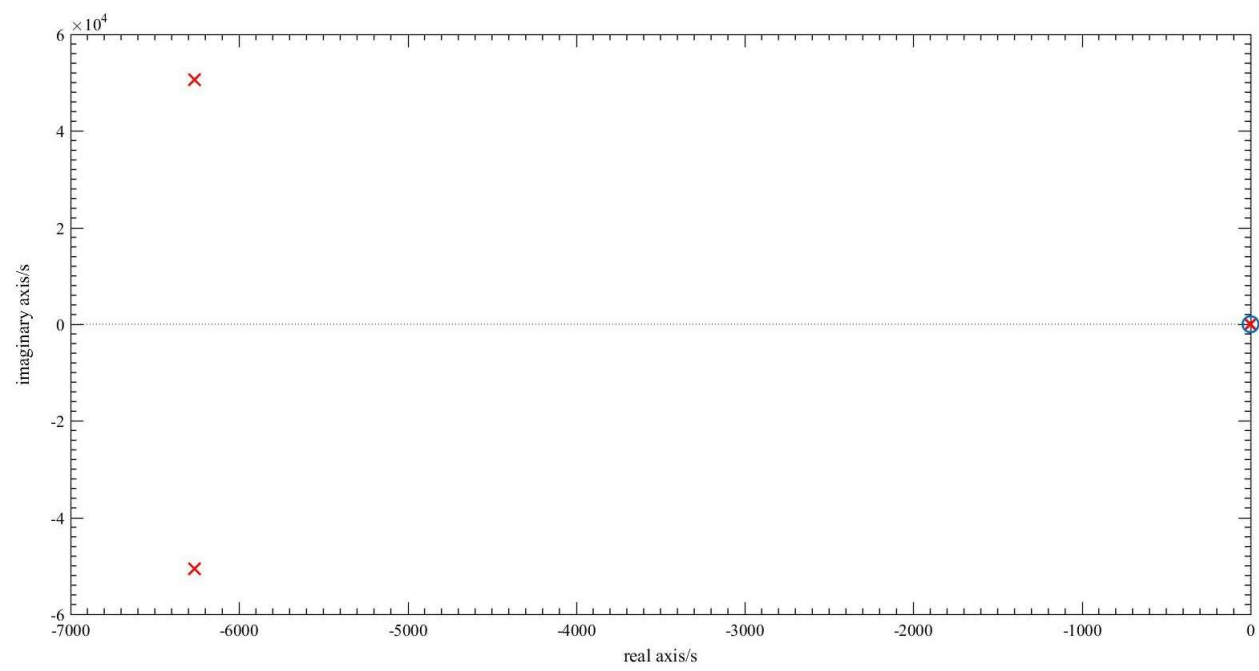

Figure 13. Root trajectory of double closed-loop control system.

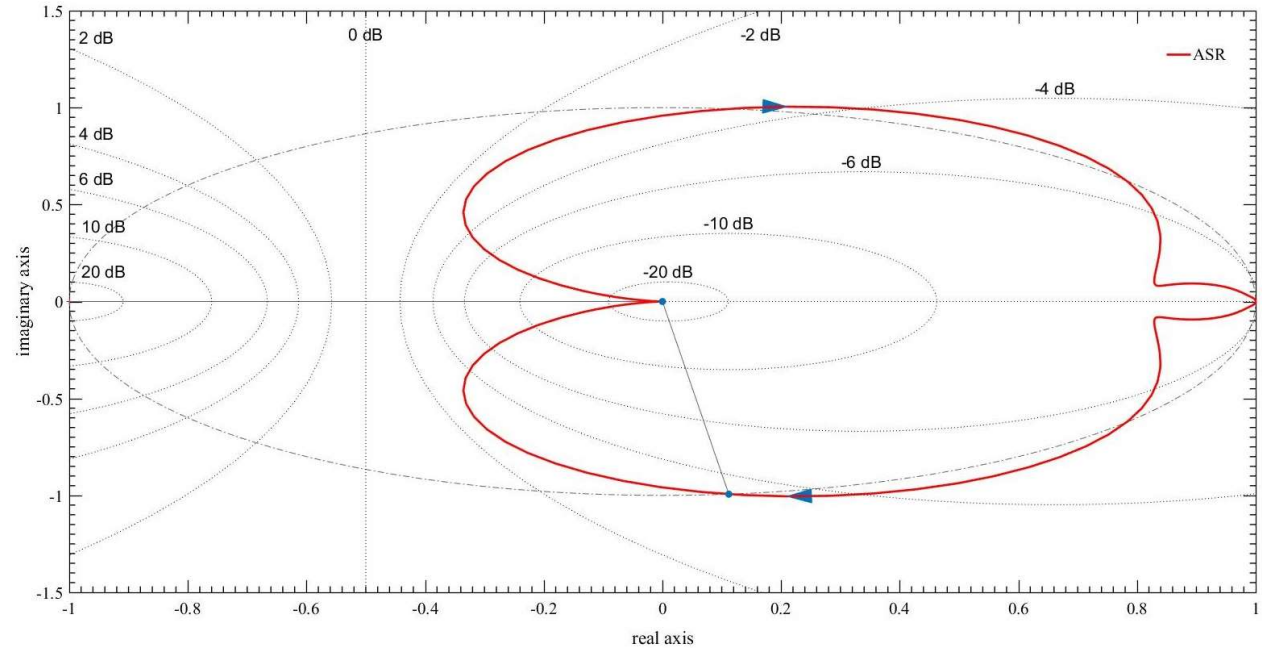

Figure 14. Nyquist diagram of double closed-loop control system.

\subsection{Motor Speed Step Response}

Figure 15a-f shows the speed step response of BLDCM at different reference speeds from 5000 to $7500 \mathrm{r} / \mathrm{min}$ under no-load. From the enlarged area drawn by extracting 0-0.02 s and 0.06-0.08 s data, it can be seen that the BLDCM control system adopting the FSNNN PID algorithm has shorter rise and adjustment time, smaller steady-state error and no overshoot, and the speed fluctuation is weaker after the speed reaches stability compared with the traditional PID and fuzzy PID algorithms. For example, the motor speed step response with reference speed at $7000 \mathrm{r} / \mathrm{min}$ is shown in Figure 15e. Table 4 shows the results of analysis of the performance indexes of speed step responses in the time domain. It can be concluded that the rise time is $7.620 \mathrm{~ms}$, the adjustment time is 8.890 $\mathrm{ms}$, and there is almost no overshoot. Furthermore, the steady-state error only is $0.0163 \%$, which means that the speed is closer to the reference speed after reaching stability.

\subsection{Phase Current and Back EMF}

Figures 16a and 17a show the three-phase current and back EMF curves under no-load of the BLDCM open loop control system. Figures $16 \mathrm{~b}-\mathrm{d}$ and $17 \mathrm{~b}-\mathrm{d}$ show the phase A, B, and $C$ current and back EMF curves under no-load with the reference speed at $7000 \mathrm{r} / \mathrm{min}$. It can be seen from Figure 16 that since the tube voltage drop and armature winding resistance are generally small, the starting current will be large in a short period of time, 
which may reach several or more than 10 times the normal operating current. The current of the motor controlled by the FSNNN PID algorithm can reach stable operation in a faster time, compared with traditional PID and fuzzy PID algorithms. In addition, from the enlarged area in Figure $17 \mathrm{~b}-\mathrm{d}$, it also can be concluded that back EMF of the motor controlled by the FSNNN PID algorithm can reach the steady-state at a faster speed, and the back EMF at the width of $120^{\circ}$ trapezoidal wave flat top is closer to the real value than traditional PID and fuzzy PID algorithms.

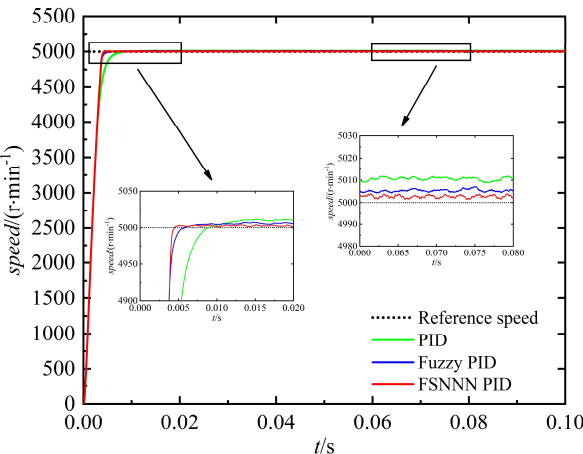

(a)

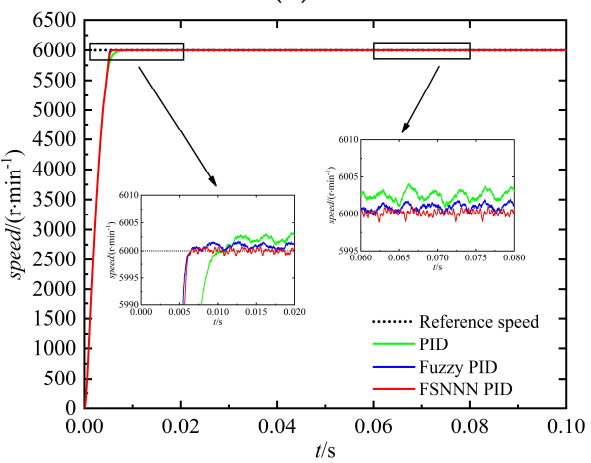

(c)

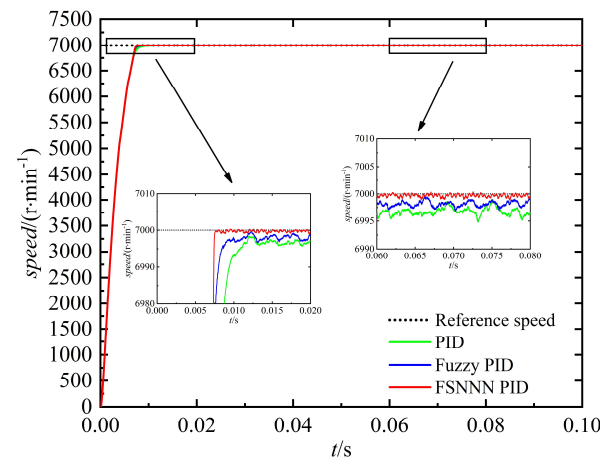

(e)

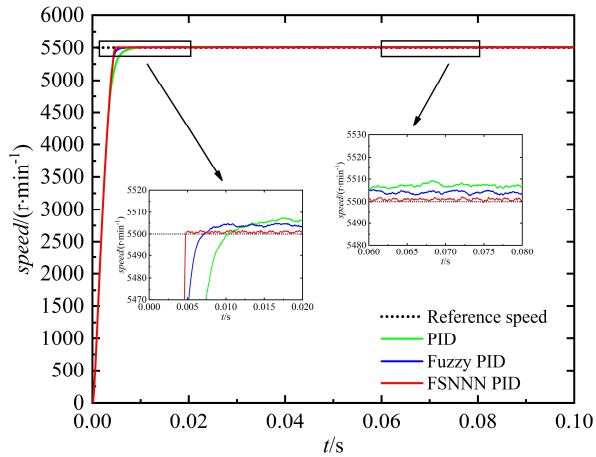

(b)

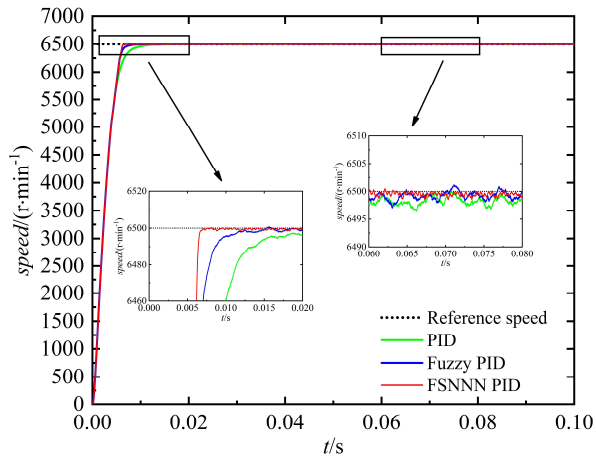

(d)

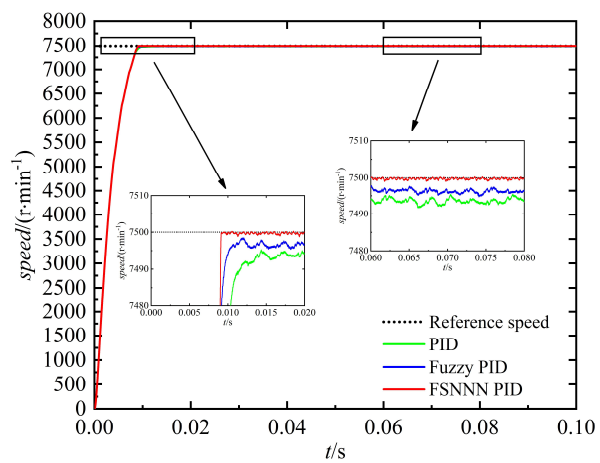

(f)

Figure 15. Speed step response of BLDCM at different reference speeds: (a) $5000 \mathrm{r} / \mathrm{min}$; (b) $5500 \mathrm{r} / \mathrm{min}$; (c) $6000 \mathrm{r} / \mathrm{min}$; (d) $6500 \mathrm{r} / \mathrm{min}$; (e) $7000 \mathrm{r} / \mathrm{min}$; (f) $7500 \mathrm{r} / \mathrm{min}$.

Table 4. Motor speed step response of $7000 \mathrm{r} / \mathrm{min}$ under different algorithms.

\begin{tabular}{cccc}
\hline \multicolumn{1}{c}{ Algorithm } & PID & \multirow{2}{*}{ Fuzzy PID } & \multirow{2}{*}{ FSNNN PID } \\
Performance Index & & & \\
\cline { 1 - 3 } rise time $t_{\mathrm{r}}$ & $11.945 \mathrm{~ms}$ & $9.945 \mathrm{~ms}$ & $7.620 \mathrm{~ms}$ \\
adjustment rise $t_{\mathrm{s}}$ & $15.895 \mathrm{~ms}$ & $13.105 \mathrm{~ms}$ & $8.890 \mathrm{~ms}$ \\
overshoot $\sigma \%$ & none & none & none \\
steady-state error & $0.0739 \%$ & $0.0451 \%$ & $0.0163 \%$ \\
\hline
\end{tabular}




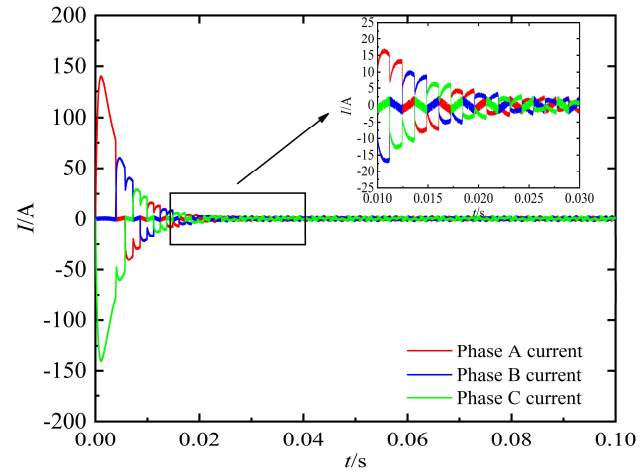

(a)

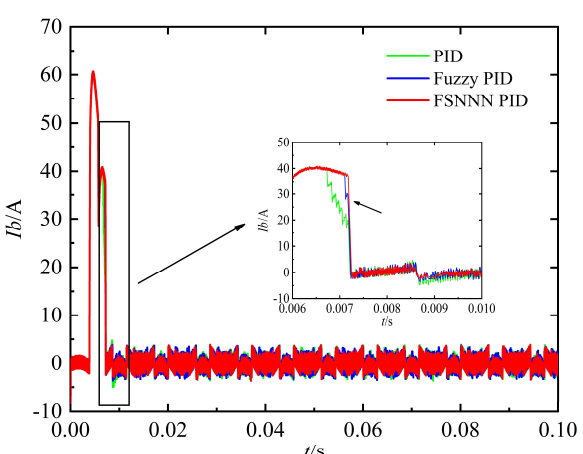

(c)

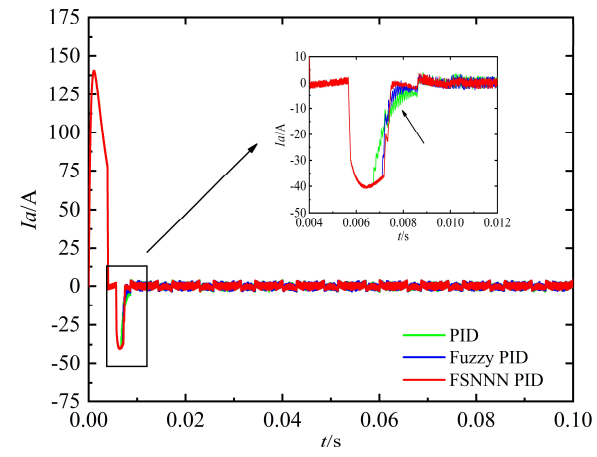

(b)

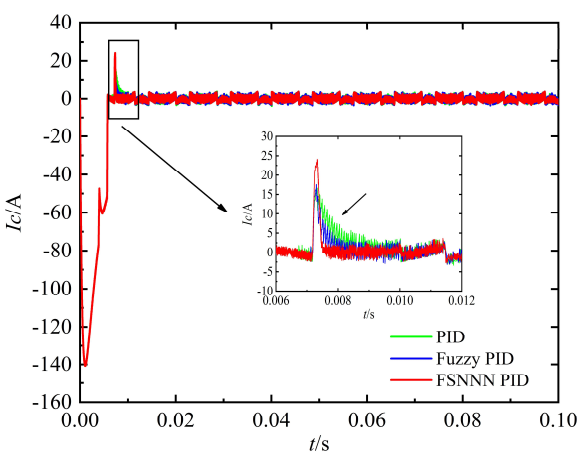

(d)

Figure 16. Current response curves at $7000 \mathrm{r} / \mathrm{min}$ under different algorithms. (a) Three phase current curves of motor under no-load open loop control; (b) phase A current; (c) phase B current; (d) phase $C$ current.

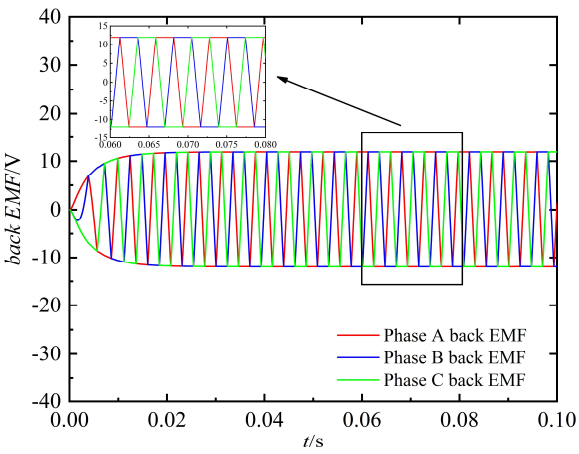

(a)

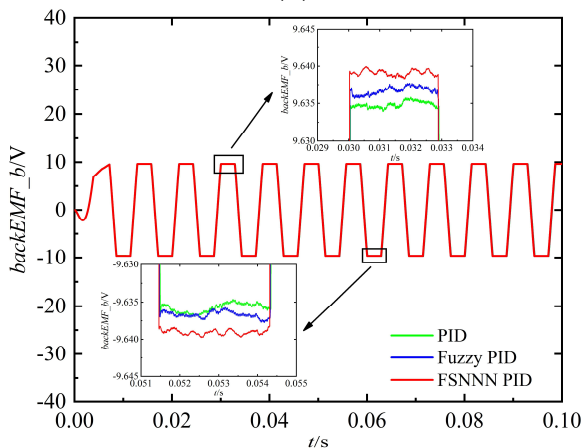

(c)

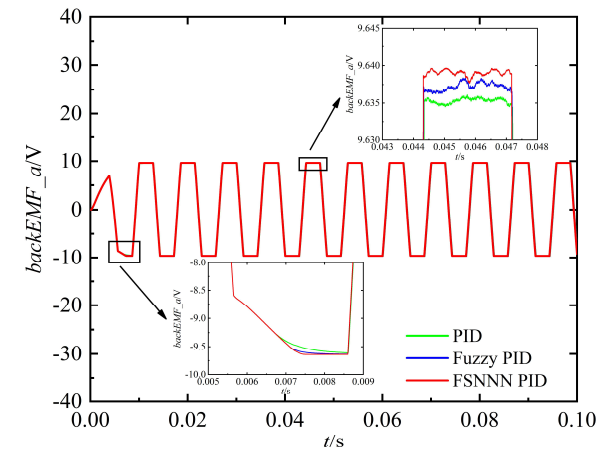

(b)

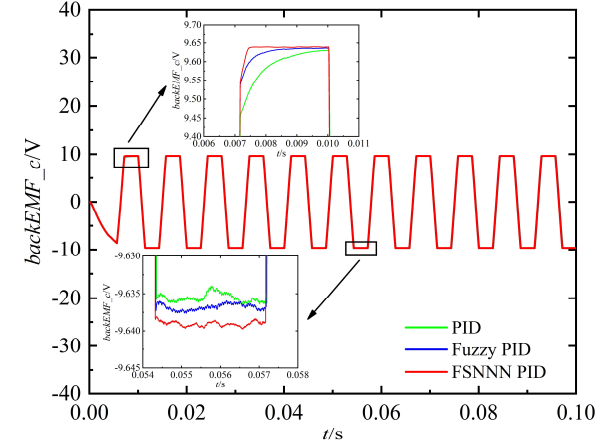

(d)

Figure 17. Back EMF curves at $7000 \mathrm{r} / \mathrm{min}$ under different algorithms. (a) Three-phase back EMF curves under no-load open loop control; (b) phase A back EMF; (c) phase B back EMF; (d) phase C back EMF. 


\subsection{Electromagnetic Torque $T_{e}$ and Rotor Angle Position $\theta$}

The relationship between motor speed $n$ and electromagnetic torque $T_{\mathrm{e}}$ with constant $U_{\mathrm{d}}$ is as follows:

$$
T_{\mathrm{e}}=K_{\mathrm{T}} \frac{30 U_{\mathrm{d}}-\pi k_{\mathrm{e}} n}{30 R}
$$

As shown in Equation (25), with a certain direct current bus voltage $U_{\mathrm{d}}$, the speed of the motor decreases upon increasing the electromagnetic torque. Figure 18 shows the electromagnetic torque curve under no-load of reference speed at $7000 \mathrm{r} / \mathrm{min}$, and Figure 19 shows the rotor angle position curve under the same working condition of double closed loop control. It can be seen from Figure 18 that the electromagnetic torque controlled by the FSNNN PID algorithm has a smaller response time and can reach steady-state at a faster speed. Similarly, in the initial stage of motor starting, because motor speed does not reach rated speed, the correlation between voltage and rotor position is poor. As shown in Figure 19, when the speed is stable, the rotor angle position is shown in the zigzag curve.

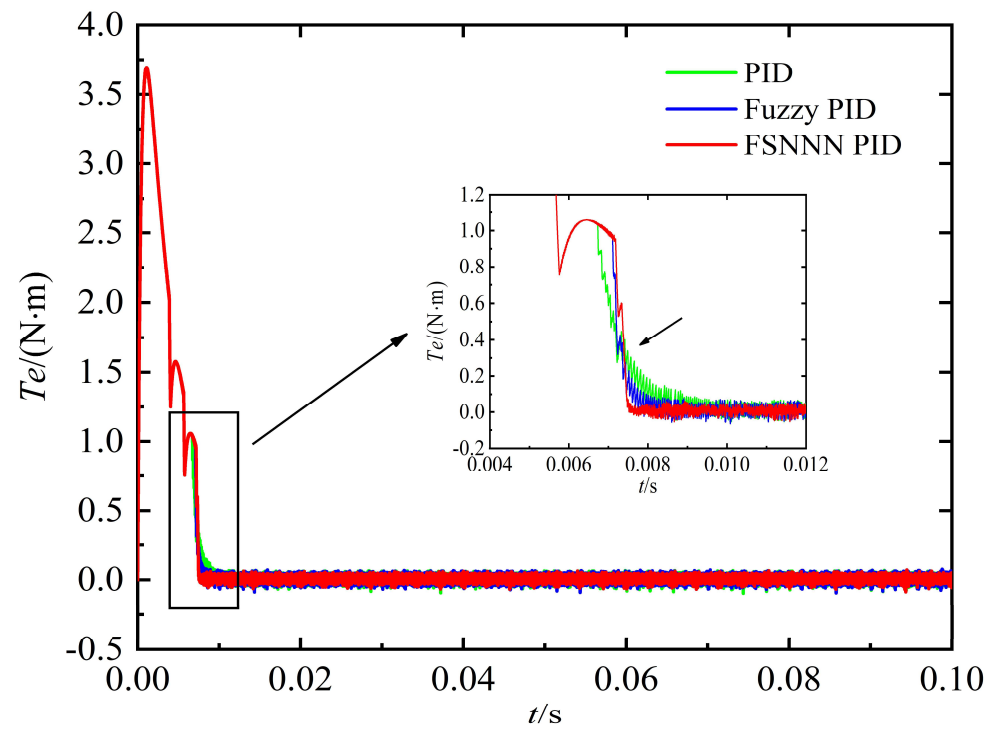

Figure 18. Electromagnetic torque $T_{\mathrm{e}}$ curve.
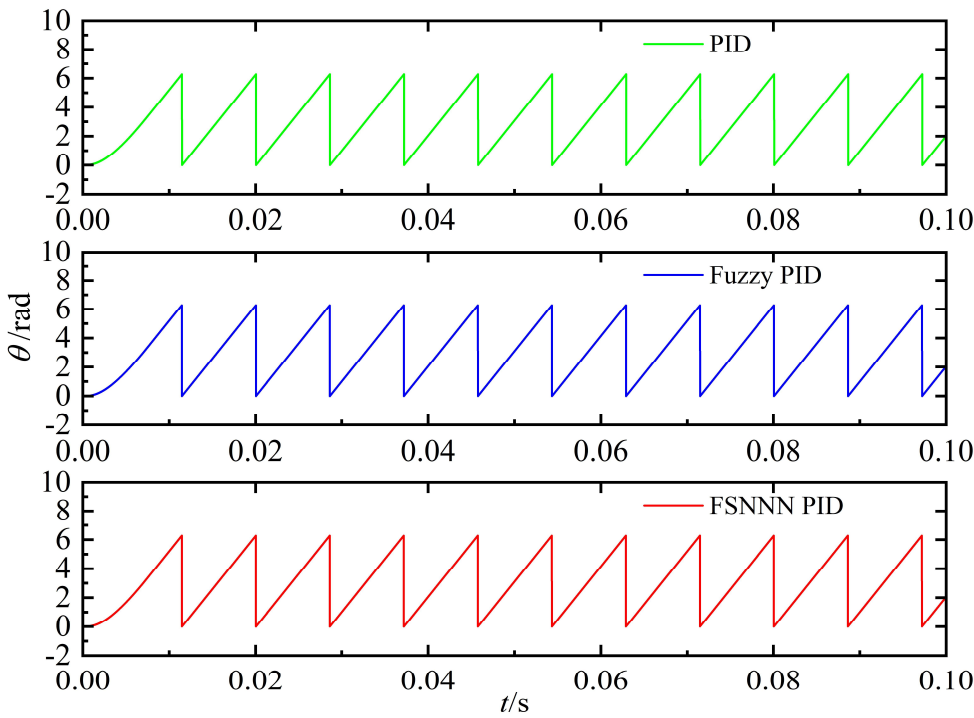

Figure 19. Rotor angle position $\theta$ curve. 


\section{Conclusions}

In this paper, a FSNNN PID algorithm is proposed and applied in ASR of a BLDCM control system. The control effects of different algorithms are analyzed and compared under different reference speeds, and the working state of three phase current, back EMF, electromagnetic torque, and rotor angle position is discussed in detail. Therefore, the following conclusions can be drawn:

(1) In the case of different reference speeds from 5000 to $7500 \mathrm{r} / \mathrm{min}$, the step response of motor speed shows that the FSNNN PID algorithm used in the BLDCM control system has a shorter rise and adjustment time, smaller steady-state error, and no overshoot than traditional PID and fuzzy PID algorithms.

(2) The stability of the motor double closed loop PID control system is verified in the frequency domain by using Bode, Root trajectory and Nyquist diagram analysis.

(3) When the reference speed is $7000 \mathrm{r} / \mathrm{min}$, three-phase current, back EMF, electromagnetic torque, and rotor angle position under control of the FSNNN PID algorithm can reach steady-state in a short time with motor speed.

Author Contributions: Conceptualization, H.Y., W.Y. and K.W.; methodology, W.Y.; software, H.Y.; validation, H.Y.; formal analysis, K.W.; resources, J.G.; data curation, H.Y.; writing-original draft preparation, H.Y. and W.Y.; writing-review and editing, J.W. and K.W.; visualization, J.W. and K.W.; supervision, J.G.; project administration, W.Y.; funding acquisition, W.Y. All authors have read and agreed to the published version of the manuscript.

Funding: This research was funded by National Natural Science Foundation of China under Grant number 11472136.

Institutional Review Board Statement: Not applicable.

Informed Consent Statement: Not applicable.

Data Availability Statement: The data presented in this paper are available upon reasonable request.

Conflicts of Interest: The authors declare no conflict of interest.

\section{References}

1. Cao, Y.; Shi, T.; Yan, Y.; Li, X.; Xia, C. Braking Torque Control Strategy for Brushless DC Motor with a Noninductive Hybrid Energy Storage Topology. IEEE Trans. Power Electron. 2020, 35, 8417-8428. [CrossRef]

2. Premkumar, K.; Manikandan, B. Adaptive Neuro-Fuzzy Inference System based speed controller for brushless DC motor. Neurocomputing 2014, 138, 260-270. [CrossRef]

3. Lee, A.-C.; Fan, C.-J.; Chen, G.-H. Current Integral Method for Fine Commutation Tuning of Sensorless Brushless DC Motor. IEEE Trans. Power Electron. 2017, 32, 9249-9266. [CrossRef]

4. Lee, Y.; Kim, W. Nonlinear position control with augmented observer in brushless dc motor. Mathematics 2021, 9, 2553. [CrossRef]

5. Terzic, B.; Jadric, M. Design and implementation of the extended Kalman filter for the speed and rotor position estimation of brushless DC motor. IEEE Trans. Ind. Electron. 2001, 48, 1065-1073. [CrossRef]

6. Xiu, J.; Wang, S.; Xiu, Y. Fuzzy adaptive single neuron NN control of brushless DC motor. Neural Comput. Appl. 2013, 22, 607-613. [CrossRef]

7. Li, W. Design of a hybrid fuzzy logic proportional plus conventional integral-derivative controller. IEEE Trans. Fuzzy Syst. 1998, 6, 449-463. [CrossRef]

8. Shi, T.; Niu, X.; Xiao, Z.; Li, X.; Xia, C. A self-tuned fuzzy-neural-network-based BLDCM speed control strategy. In Proceedings of the 8th IET International Conference on Power Electronics, Machines and Drives (PEMD 2016), Glasgow, UK, 19-21 April 2016. [CrossRef]

9. Qiao, Z.; Shi, T.; Wang, Y.; Yan, Y.; Xia, C.; He, X. New Sliding-Mode Observer for Position Sensorless Control of Permanent-Magnet Synchronous Motor. IEEE Trans. Ind. Electron. 2013, 60, 710-719. [CrossRef]

10. Gan, M.-G.; Zhang, M.; Zheng, C.-Y.; Chen, J. An adaptive sliding mode observer over wide speed range for sensorless control of a brushless DC motor. Control. Eng. Pract. 2018, 77, 52-62. [CrossRef]

11. Navidi, N.; Bavafa, M.; Hesami, S. A new approach for designing of PID controller for a linear brushless dc motor with using ant colony search algorithm. In Proceedings of the 2009 Asia-Pacific Power and Energy Engineering Conference, Wuhan, China, 19-31 March 2009. [CrossRef]

12. Shi, P.J.; Shi, G.B.; Lin, Y. A nonlinear PI controller of the brushless DC motor based on ant colony system. In Proceedings of the 2008 International Conference on Electrical Machines and Systems, Wuhan, China, 17-20 October 2008. 
13. Lin, C.-L.; Jan, H.-Y.; Shieh, N.-C. GA-based multiobjective PID control for a linear brushless DC motor. IEEE/ASME Trans. Mechatron. 2003, 8, 56-65. [CrossRef]

14. Chen, G.Y.; Perng, J.-W. PI speed controller design based on GA with time delay for BLDC motor using DSP. In Proceedings of the 2017 IEEE International Conference on Mechatronics and Automation (ICMA), Takamatsu, Japan, 6-9 August 2017; pp. 1174-1179. [CrossRef]

15. Ridwan, M.; Riawan, D.C.; Suryoatmojo, H. Particle swarm optimization-based BLDC motor speed controller with response speed consideration. In Proceedings of the 2017 International Seminar on Intelligent Technology and Its Applications (ISITIA), Surabaya, Indonesia, 28-29 August 2017; pp. 193-198. [CrossRef]

16. Ramya, M.A.; Jadhav, S.P.; Pawar, S.N. Design and implementation of particle swarm optimization (PSO) tuned PID controller for speed control of permanent magnet brushless DC (PMBLDC) motor. In Proceedings of the 2020 International Conference for Emerging Technology (INCET), Belgaum, India, 5-7 June 2020. [CrossRef]

17. El-Samahy, A.A.; Shamseldin, M.A. Brushless DC motor tracking control using self-tuning fuzzy PID control and model reference adaptive control. Ain Shams Eng. J. 2018, 9, 341-352. [CrossRef]

18. Liu, Y.; Zhao, J.; Xia, M.; Luo, H. Model Reference Adaptive Control-Based Speed Control of Brushless DC Motors with Low-Resolution Hall-Effect Sensors. IEEE Trans. Power Electron. 2013, 29, 1514-1522. [CrossRef]

19. Rubaai, A.; Ricketts, D.; Kankam, M. Experimental verification of a hybrid fuzzy control strategy for a high-performance brushless DC drive system. IEEE Trans. Ind. Appl. 2001, 37, 503-512. [CrossRef]

20. Nandakumar, M.; Ramalingam, S.; Nallusamy, S.; Rangarajan, S.S. Novel Efficacious Utilization of Fuzzy-Logic Controller-Based Two-Quadrant Operation of PMBLDC Motor Drive Systems for Multipass Hot-Steel Rolling Processes. Electronics 2020, 9, 1008. [CrossRef]

21. Sadrossadat, S.A.; Rahmani, O. ANN-based method for parametric modelling and optimising efficiency, output power and material cost of BLDC motor. IET Electr. Power Appl. 2020, 14, 951-960. [CrossRef]

22. Peng, J.; Dubay, R. Identification and adaptive neural network control of a DC motor system with dead-zone characteristics. ISA Trans. 2011, 50, 588-598. [CrossRef]

23. Hiyama, T.; Kugimiya, M.; Satoh, H. Advanced PID type fuzzy logic power system stabilizer. IEEE Trans. Energy Convers. 1994, 9 , 514-520. [CrossRef]

24. Wang, J.; Fu, C.; Zhang, Y. SVC Control System Based on Instantaneous Reactive Power Theory and Fuzzy PID. IEEE Trans. Ind. Electron. 2008, 55, 1658-1665. [CrossRef]

25. Savran, A.; Kahraman, G. A fuzzy model based adaptive PID controller design for nonlinear and uncertain processes. ISA Trans. 2014, 53, 280-288. [CrossRef] [PubMed]

26. Lotfi, M.; Menhaj, M.B.; Hosseini, S.A.; Shirani, A.S. A design of switching supervisory control based on fuzzy-PID controllers for VVER-1000 pressurizer system with RELAP5 and MATLAB coupling. Ann. Nucl. Energy 2020, 147, 107625. [CrossRef]

27. Peng, X.W.; Gao, H.L. Improved diagonal recursion neural network and PI control of permanent magnet synchronous motor. Electr. Mach. Control 2019, 23, 126-132. [CrossRef]

28. Mcculloch, W.S.; Pitts, W. A logical calculus of the ideas immanent in nervous activity. Bull. Math. Biophys. 1943, 5, 115-133. [CrossRef]

29. Rosenblatt, F. The perceptron: A probabilistic model for information storage and organization in the brain. Psychol. Rev. 1958, 65, 386-408. [CrossRef]

30. Rumelhart, D.E.; Hinton, G.E.; Williams, R.J. Learning representations by back-propagating errors. Nature 1986, 323, 533-536. [CrossRef]

31. Hinton, G.E.; Salakhutdinov, R.R. Reducing the Dimensionality of Data with Neural Networks. Science 2006, 313, 504-507. [CrossRef]

32. Yu, C.; Li, Y.; Bao, Y.; Tang, H.; Zhai, G. A novel framework for wind speed prediction based on recurrent neural networks and support vector machine. Energy Convers. Manag. 2018, 178, 137-145. [CrossRef]

33. Gao, W.; Zhou, P. Customized High Performance and Energy Efficient Communication Networks for AI Chips. IEEE Access 2019, 7, 69434-69446. [CrossRef]

34. Esquivel, N.; Nicolis, O.; Peralta, B.; Mateu, J. Spatio-Temporal Prediction of Baltimore Crime Events Using CLSTM Neural Networks. IEEE Access 2020, 8, 209101-209112. [CrossRef]

35. Wei, S.; Wang, J.; Ou, J. Method for improving the neural network model of the magnetorheological damper. Mech. Syst. Signal Process. 2021, 149, 107316. [CrossRef]

36. Chhipa, A.A.; Kumar, V.; Joshi, R.R.; Chakrabarti, P.; Jasinski, M.; Burgio, A.; Leonowicz, Z.; Jasinski, E.; Soni, R.; Chakrabarti, T. Adaptive Neuro-Fuzzy Inference System-Based Maximum Power Tracking Controller for Variable Speed WECS. Energies 2021, 14, 6275. [CrossRef]

37. Qiao, J.-F.; Hou, Y.; Zhang, L.; Han, H.-G. Adaptive fuzzy neural network control of wastewater treatment process with multiobjective operation. Neurocomputing 2018, 275, 383-393. [CrossRef]

38. Ali, M.S.; Gunasekaran, N.; Zhu, Q. State estimation of T-S fuzzy delayed neural networks with markovian jumping parameters using sampled-data control. Fuzzy Sets Syst. 2017, 306, 87-104. [CrossRef]

39. Guan, C.; Wang, S.; Liew, A.W.-C. Lip image segmentation based on a fuzzy convolutional neural network. IEEE Trans. Fuzzy Syst. 2019, 28, 1242-1251. [CrossRef] 
40. Varela-Santos, S.; Melin, P. A new modular neural network approach with fuzzy response integration for lung disease classification based on multiple objective feature optimization in chest X-ray images. Expert Syst. Appl. 2021, 168, 114361. [CrossRef]

41. Zhang, Y.; Ma, H.; Xu, J. Neural network-based fuzzy vibration controller for offshore platform with random time delay. Ocean Eng. 2021, 225, 108733. [CrossRef]

42. Yin, H.; Yi, W.; Wang, K.; Guan, J.; Wu, J. Research on brushless DC motor control system based on fuzzy parameter adaptive PI algorithm. AIP Adv. 2020, 10, 105208. [CrossRef]

43. Bennett, S. Development of the PID controller. IEEE Control. Syst. 1993, 13, 58-62. [CrossRef] 